\title{
$\bullet$ Neuropathy in Newly Diagnosed Hyperthyroid Patients: A Case-Control Study
}

\author{
IJCRR \\ Section: Healthcare \\ ISI Impact Factor \\ (2019-20): 1.628 \\ IC Value (2019): 90.81 \\ SJIF (2020) $=7.893$

\author{
Ahmad Faraz ${ }^{1}$, Sangeeta Singhal' ${ }^{1}$, M. Mobarak Hossain ${ }^{1}$, S. S. Siddiqui² \\ 'Department of Physiology, JNMC, AMU, Aligarh, UP, India; ${ }^{2}$ Rajiv Gandhi Centre for Diabetes and Endocrinology, AMU, Aligarh, UP, lndia.
}

\section{ABSTRACT}

Introduction: Hyperthyroidism is a common endocrinologic disorder affecting many organ systems. Several neurological diseases like acute and chronic myopathy, periodic paralysis, ophthalmoplegia, and rarely myasthenia gravis are known associations of thyrotoxicosis. However, neuropathy in hyperthyroidism is not frequently reported.

Objective: To evaluate the occurrence of neuropathy in hyperthyroid patients.

Methods: 60 patients of hyperthyroidism were included in the study, detailed history and clinical examination was performed. 60 normal subjects were included as a control. Nerve Conduction Studies were performed in neurophysiology lab of Physiology dept of JNMC Aligarh.

Result: While comparing motor conduction parameters of hyperthyroid patients with the control group, NCV and Latencies do not show a significant difference, while the Amplitude of the Median Nerve in both the limbs shows a significant decrease. On comparing Sensory conduction parameters of hyperthyroid patients with the control group, the amplitude of the Median Nerve, Sural Nerve shows a significant decrease, while latencies of Median Nerve and Sural Nerve is increased in hyperthyroid patients.

Conclusion: Our study indicates predominant sensorimotor axonal neuropathy in newly diagnosed hyperthyroid patients. We suggest neurological investigation should be included at the time of diagnosis in these patients.

Key Words: Hyperthyroidism, Neurophysiology, Nerve Conduction Velocity, Neuropathy, Sensorimotor Neuropathy, Sensory Nerve Conduction Velocity, Motor Nerve Conduction Velocity

\section{INTRODUCTION}

The thyroid hormone is required by cells and tissues for basic metabolism for their normal functioning. The thyroid hormone has profound impacts on prenatal and even during postnatal life on the developing brain. ${ }^{1,2}$ The thyroid hormone also plays an important part in the growth of the brain and spinal cord and myelination of neurons in adults. Prevalence of Hyperthyroidism is increased in urban population and the highest prevalence is found in the age group of $30-49$ years. ${ }^{3}$ Hyperthyroidism is characterized by heat intolerance, sweating, increased pulse pressure, a fine tremor of the outstretched fingers, tachycardia, atrial fibrillation in the elderly, hyperreflexia, hyperactivity, irritability, muscle weakness, proximal myopathy. ${ }^{4}$ Musculoskeletal and neurological involvement often manifests as fatigue, muscle weakness, and paralysis. Thyrotoxicosis is associated with various neurological diseases like acute and chronic myopathy, periodic paralysis, ophthalmoplegia, and rarely myasthenia gravis. Neuromuscular association and primary muscle disorder are associated with hyperthyroidism. ${ }^{5}$ However, neuropathy in hyperthyroidism is not frequently reported. Our study aims to find out the effect of hyperthyroidism in neuropathy.

\section{MATERIALS AND METHODS}

Ethical clearance was taken from the ethical committee of J.N. Medical College. Patients attending the Rajiv Gandhi Centre for diabetes and Endocrinology were evaluated for inclusion and exclusion criteria. Patients who gave valid written and informed consent were included in the study.

\section{Corresponding Author:}

Ahmad Faraz, Department of Physiology, J. N Medical College, Aligarh Muslim University, Aligarh, Uttar Pradesh, India. Phone:+919997625257; Email:afaraz83@gmail.com

ISSN: 2231-2196 (Print)

Received: 23.08 .2020
ISSN: 0975-5241 (Online)

Revised: 12.10 .2020
Accepted: 09.11.2020
Published: 16.02 .2021 


\section{Study population}

Sixty patients of newly diagnosed hyperthyroidism defined by decreased Thyroid Stimulating Hormone (TSH) and raised FT4 were taken from Rajiv Gandhi Centre of Diabetes and Endocrinology. Patients with overt hyperthyroidism were included in the study. Patients having Diabetes Mellitus, Hypertension, and Renal failure, alcoholic hepatitis, vitamin B12 deficiency, patients taking steroids, neuropathies associated with malnutrition, toxic agents e.g. metal or drugs, and neuropathy from other conditions were excluded from the study. Sixty normal subjects who gave informed consent and are willing to participate in the study were included in our study.

\section{Clinical Evaluation}

Patients included in the study were screened for neuromuscular symptoms such as weakness, tiredness, myalgia, stiffness, cramps, numbness, tingling, pain, and paraesthesia. Neurological examination for motor and the sensory system was done, it includes Pin-prick, light touch, and vibration sensation evaluation of cranial nerves, motor power, and reflexes.

\section{Nerve Conduction Studies}

\section{MNCV}

NCS was carried out according to standardized protocols for the bilateral median, ulnar, and common peroneal nerve. The negative end of the stimulator was positioned near to the active electrode. The surface recording electrodes were used and placed in belly tendon montage; the active electrode is placed adjacent to the motor point and reference near to tendon. A ground electrode has been positioned between the stimulating and the recording electrodes. Stimulation intensity was slowly raised and the value at which the amplitude did not increase was calculated as the supramaximal strength. This stimulation intensity was used to record a Compound Muscle Action Potential (CMAP). At two points along its path, motor or mixed nerve was stimulated. Distance has been calculated in mm between two points of stimulation, Motor Nerve Conduction Velocity (MNCV) was calculated by dividing distance and latency difference between the proximal and the distal latencies (ms). The nerve conduction velocity is expressed as $\mathrm{m} / \mathrm{s}$ and amplitude in $\mathrm{mv}^{6}{ }^{6}$

\section{SNCV}

In our study sensory nerves were tested by antidromic recording. In an antidromic conduction study, the proximal point of a nerve is stimulated and distally, Sensory Nerve Action Potential (SNAP) is recorded. In Sensory Conduction study averaging of signal enhancement is required. The averaged signal enhancement is directly proportional to the square root of the no. of trials. The latency of potential is calculated from the stimulus artefact to the initial positive peak. SNCV unlike MNCV is measured by stimulating at a single stimulation site since sensory nerve conduction does not include neuromuscular transmission time and muscle propagation time. Thus, the SNCV was calculated by dividing the distance $(\mathrm{mm})$ between the stimulating and recording sites by the latency $(\mathrm{ms})$. The nerve conduction velocity is expressed as $\mathrm{m} / \mathrm{s}^{5}$

\section{Statistical analyses}

Analyses were done using SPSS 21.0. Data were expressed as mean $\pm \mathrm{SD}$, the normalcy of data was assessed by the Kolmogorov Smirnoff test. Unpaired t-tests were used for comparison between quantitative variables. Chi-square tests were used to compare differences in the categorical variables. The confidence interval (CI) was set at 95\%.

\section{RESULTS}

We evaluated 85 patients of hyperthyroidism and they were assessed for inclusion and exclusion criteria. 60 subjects were included in the study who gave valid consent and were newly diagnosed hyperthyroid patients and met with inclusion criteria. and 60 normal subjects. The mean age of hyperthyroid patients was $33.2 \pm 3.58$ and that of control is $32.1 \pm 3.81$ and is statistically non-significant. 18 patients $(30 \%)$ presented with a tingling sensation in lower limbs, 20 (33.3\%) patients complain of numbness, 6 patients presented with pain. TSH level of Hyperthyroid patients is less than $0.02 \mathrm{mU} / 1$ and FT4 is $50.6 \pm 3.4$.

On comparing motor conduction parameters in hyperthyroid patients with a control group, NCV and Latencies do not show a significant difference, while Amplitude of Median Nerve in both the limbs (Rt median: $9.41 \pm 3.2$, Lt Median: $10.12 \pm 4.5$ ) shows a significant decrease (Table 1).

While comparing Sensory conduction parameters in hyperthyroid patients with a control group, the amplitude of Median Nerve (Rt Median Nerve: $26.71 \pm 5.9$, Lt Median Nerve: $28.32 \pm 6.2$ ), Sural Nerve (Rt Sural Nerve: $22.80 \pm 2.6, \mathrm{Lt}$ Sural Nerve: $21.73 \pm 3.6$ ) shows a significant decrease, while latencies of Median Nerve (Rt Median Nerve: $3.69 \pm .69, \mathrm{Lt}$ Median Nerve: $3.43 \pm .80$ ) and Sural Nerve (Rt Sural Nerve: $3.31 \pm .62$, Lt Sural Nerve:3.29 \pm .59 ) is increased in hyperthyroid patients when compared with control (Table 2).

Table 1: Comparison between Motor Nerve Conduction Velocity (MNCV) of various nerves in both the Hyperthyroid $(n=60)$ and the control subjects $(n=60)$

$\begin{array}{lccc}\text { PARAMETER } & \begin{array}{c}\text { CONTROL } \\ \mathbf{M} \pm \mathbf{S D}\end{array} & \begin{array}{c}\text { CASE } \\ \mathbf{M} \pm \mathrm{SD}\end{array} & \text { p-Value } \\ \text { Median MNCV (Right) } & 60.68 \pm 6.79 & 59.23 \pm 7.35 & >.05 \\ \text { Median MNCV (Left) } & 62.21 \pm 4.59 & 61.68 \pm 4.51 & >.05\end{array}$


Table 1: (Continued)

\begin{tabular}{|c|c|c|c|}
\hline PARAMETER & $\begin{array}{l}\text { CONTROL } \\
\mathrm{M} \pm \mathrm{SD}\end{array}$ & $\begin{array}{l}\text { CASE } \\
\mathbf{M} \pm \mathrm{SD}\end{array}$ & p-Value \\
\hline Ulnar MNCV (Right) & $63.3 \pm 10.7$ & $61.46 \pm 8.34$ & $>.05$ \\
\hline Ulnar MNCV (Left) & $63.19 \pm 6.65$ & $62.13 \pm 8.17$ & $>.05$ \\
\hline $\begin{array}{l}\text { Common Peroneal } \\
\text { MNCV (Right) }\end{array}$ & $52.28 \pm 6.18$ & $49.9 \pm 7.23$ & $>.05$ \\
\hline $\begin{array}{l}\text { Common Peroneal } \\
\text { MNCV (Left) }\end{array}$ & $54.79 \pm 6.52$ & $51.95 \pm 6.14$ & $>.05$ \\
\hline $\begin{array}{l}\text { Median Latency } \\
\text { (Right) }\end{array}$ & $3.30 \pm .50$ & $3.69 \pm 1.2$ & $>.05$ \\
\hline Median Latency (Left) & $3.43 \pm .68$ & $3.80 \pm 0.9$ & $>.05$ \\
\hline Ulnar Latency (Right) & $3.07 \pm .44$ & $3.24 \pm .70$ & $>.05$ \\
\hline Ulnar Latency (Left) & $3.23 \pm .59$ & $3.12 \pm .57$ & $>.05$ \\
\hline $\begin{array}{l}\text { Common Peroneal } \\
\text { Latency (Right) }\end{array}$ & $4.48 \pm .72$ & $4.28 \pm .78$ & $>.05$ \\
\hline $\begin{array}{l}\text { Common Peroneal } \\
\text { Latency (Left) }\end{array}$ & $4.78 \pm .96$ & $4.89 \pm .87$ & $>.05$ \\
\hline $\begin{array}{l}\text { Median N Amplitude } \\
\text { (Right) }\end{array}$ & $11.38 \pm 2.5$ & $9.41 \pm 3.2$ & $<.05$ \\
\hline $\begin{array}{l}\text { Median N Amplitude } \\
\text { (Left) }\end{array}$ & $12.68 \pm 3.4$ & $10.12 \pm 4.5$ & $<.05$ \\
\hline $\begin{array}{l}\text { Ulnar N Amplitude } \\
\text { (Right) }\end{array}$ & $5.14 \pm 1.9$ & $4.67 \pm 2.3$ & $>.05$ \\
\hline $\begin{array}{l}\text { Ulnar N Amplitude } \\
\text { (Left) }\end{array}$ & $4.95 \pm 2.1$ & $4.01 \pm 3.4$ & $>.05$ \\
\hline $\begin{array}{l}\text { Common Peroneal N } \\
\text { Amplitude (Right) }\end{array}$ & $5.60 \pm 1.4$ & $5.10 \pm 2.7$ & $>.05$ \\
\hline $\begin{array}{l}\text { Common Peroneal N } \\
\text { Amplitude (Left) }\end{array}$ & $5.20 \pm 1.6$ & $4.60 \pm 1.9$ & $>.05$ \\
\hline
\end{tabular}

*P Value: $<0.05$

Table 2: Comparison between Sensory Nerve Conduction Velocity (SNCV) of various nerves in both the Hyperthyroid $(n=60)$ and the control subjects $(n=60)$

\begin{tabular}{lccc} 
PARAMETER & $\begin{array}{c}\text { Control } \\
\mathbf{M} \pm \text { SD }\end{array}$ & $\begin{array}{c}\text { Case } \\
\mathbf{M} \pm \text { SD }\end{array}$ & p Value \\
\hline Median SNCV(Right) & $51.59 \pm 8.10$ & $54.83 \pm 6.76$ & $>.05$ \\
Median SNCV(Left) & $50.59 \pm 8.27$ & $53.54 \pm 7.22$ & $>.05$ \\
Ulnar SNCV (Right) & $54.17 \pm 8.07$ & $52.51 \pm 7.66$ & $>.05$ \\
Ulnar SNCV (Left) & $54.91 \pm 7.21$ & $56.53 \pm 6.70$ & $>.05$ \\
Sural SNCV(Right) & $43.87 \pm 6.43$ & $45.69 \pm 7.32$ & $>.05$ \\
Sural SNCV(Left) & $43.6 \pm 6.35$ & $46.24 \pm 6.86$ & $>.05$ \\
Median Latency & $3.14 \pm .56$ & $3.69 \pm .69$ & $<.05^{*}$ \\
(Right) & & & \\
Median Latency (Left) & $3.03 \pm .43$ & $3.43 \pm .80$ & $<.05^{*}$ \\
Ulnar Latency (Right) & $2.85 \pm .39$ & $3.05 \pm .52$ & $>.05$ \\
Ulnar Latency (Left) & $2.96 \pm .50$ & $3.21 \pm .50$ & $>.05$ \\
Sural Latency (Right) & $2.81 \pm .45$ & $3.31 \pm .62$ & $<.05^{*}$
\end{tabular}

Table 2: (Continued)

\begin{tabular}{lccc} 
PARAMETER & $\begin{array}{c}\text { Control } \\
\text { M } \pm \text { SD }\end{array}$ & $\begin{array}{c}\text { Case } \\
\mathbf{M} \pm \text { SD }\end{array}$ & p Value \\
\hline $\begin{array}{l}\text { Sural Latency (Left) } \\
2.75 \pm .37\end{array}$ & $3.29 \pm .59$ & $<.05^{*}$ \\
$\begin{array}{l}\text { Median N Amplitude } \\
\text { (Right) }\end{array}$ & $30.25 \pm 6.4$ & $26.71 \pm 5.9$ & $<.05^{*}$ \\
$\begin{array}{l}\text { Median N Amplitude } \\
\text { (Left) }\end{array}$ & $31.75 \pm 7.7$ & $28.32 \pm 6.2$ & $<.05^{*}$ \\
$\begin{array}{l}\text { Ulnar N Amplitude } \\
\text { (Right) }\end{array}$ & $30.34 \pm 6.5$ & $29.02 \pm 5.8$ & $>.05$ \\
$\begin{array}{l}\text { Ulnar N Amplitude } \\
\text { (Left) }\end{array}$ & $32.01 \pm 5.2$ & $33.12 \pm 6.3$ & $>.05$ \\
$\begin{array}{l}\text { Sural N Amplitude } \\
\text { (Right) }\end{array}$ & $24.38 \pm 3.4$ & $22.80 \pm 2.6$ & $<.05^{*}$ \\
$\begin{array}{l}\text { Sural N Amplitude } \\
\text { (Left) }\end{array}$ & $23.56 \pm 2.9$ & $21.73 \pm 3.6$ & $<.05^{*}$ \\
\hline
\end{tabular}

*P Value: $<0.05$

\section{DISCUSSION}

In the present study, our results showed that the amplitude of the median and sural nerve in hyperthyroid patients is significantly decreased as compared to the control group. The latency of the sural nerve is increased, while the Nerve Conduction Velocity of these nerves showed no significant results. Duyff et $\mathrm{al}^{7}$ in their study concluded that $20 \%$ of Hyperthyroid patients present with sensorimotor axonal polyneuropathy, they also pointed a very good response to neuropathy by anti-thyroid treatment. MNCV of the median nerve, ulnar nerve, and common peroneal nerve in the hyperthyroid subject is not decreased. ${ }^{13}$ Yüksel et $\mathrm{al}^{8}$ shows increased latency of sural nerve in hyperthyroid patients.

A comparison of the SNCV does not show a significant decrease in the conduction velocity of the median, ulnar, and common peroneal nerve in hyperthyroid subjects as compared to the SNCV of these nerves in the control subjects. But sensory latency of the Sural nerve is increased bilaterally in hyperthyroid subjects as compared to control subjects. In hyperthyroid cases latency of sural nerve is increased when compared with normal subjects. Feibel and Campa concluded that their patient of hyperthyroidism presented with a latent sensorimotor polyneuropathy. ${ }^{9}$ Ludin et al. (1969) show neuropathic involvement in hyperthyroidism, they hypothesized that their patients had a subclinical polyneuropathy. ${ }^{10}$ Roquer et al., (1993) in their prospective study, found Carpal Tunnel Syndrome (CTS)in 5\% of hyperthyroid patients in the initial survey. They concluded that CTS should be considered another peripheral neurological manifestation associated with hyperthyroidism. ${ }^{11}$ Sözay et al., (1994) show a decrease in the amplitude of sensory nerves. The SNCV of the sural nerve is decreased by $35.5 \%$. They concluded that electrophysiological studies can be an important diagnostic 
tool for asymptomatic hyperthyroid patients. ${ }^{12}$ Sweed et al., (2007) conducted their study on hyperthyroidism in geriatric patients, they revealed evidence of motor neuropathy in the upper limb of axonal type. The prevalence of affection in the hyperthyroid group was found in $25 \%$ of cases. Also, entrapment neuropathy of the median nerve has been observed in $25 \%$ of hyperthyroid patients..$^{13} \mathrm{~A}$ case report on the hyperthyroid patient reveals acute polyneuropathy in hyperthyroidism..$^{14}$ Ajeena, (2013) concluded that in hyperthyroid patients, nerve conduction parameters were not significant when compared with that of the control group. But they also said that there were $10(32.2 \%)$ hyperthyroid patients, where the sural nerve was the most commonly involved, and 10 (32.2\%) of them had CTS. ${ }^{15}$ Although the reason for neuropathy in hyperthyroid patients is still known, it has been hypothesized to be either a direct effect of increased thyroid hormones, immune-mediated or due to a hypermetabolic state reducing these essential nutrients of nerves. ${ }^{16}$ Further studies are required to ascertain the exact cause. Various studies suggest myopathy as a predominant manifestation of hyperthyroidism, but we cannot deny the fact that neuropathy is also associated with hyperthyroidism. The amplitude of the Median nerve and the Sural nerve is decreased which suggests that there is sensorimotor axonal neuropathy. Further several studies pointed in this direction. The exact pathogenesis is still not known.

\section{CONCLUSION}

Neuropathy in hyperthyroidism is an underdiagnosed condition, most studies correlate myopathy with hyperthyroidism. But our study indicates predominant sensorimotor axonal neuropathy in newly diagnosed hyperthyroid patients. We suggest neurological investigation should be included at the time of diagnosis in these patients. Further studies should be done to find out the pathogenesis of neuropathy in hyperthyroidism.

\section{ACKNOWLEDGMENT}

We would like to acknowledge the support provided by Aley Mustafa. We would like to thank the Department of Physiology and Rajiv Gandhi Centre for Diabetes and Endocrinology for the smooth running of the study.

Conflict of interest: None of the authors declared any conflict of interest
Funding: The Study was self-financed.

\section{REFERENCES}

1. Bernal J. Iodine and brain development. Biofactors 1999;10:271276.

2. Oppenheimer JH, Schwartz HL. Molecular basis of thyroid hormone-dependent brain development. Endocr Rev 1997; 18: 462-475.

3. Deokar PG, Nagdeote AN, Lanje MJ, Basutkar DG. Prevalence of Thyroid Disorders in A Tertiary Care Center. Int J Cur Res Rev 2016; 8(9):26- 30.

4. Tonner DR, Schlechte JA. Neurological complications of the thyroid and parathyroid disease. Med Clin North Am 1993;77:251263.

5. Fisher M, Matell JE, Ullrich I, Gutrecht JA. Pyramidal tract deficits and poly-neuropathy in hyperthyroidism. Am J Med 1985;78:1041-1044.

6. Mishra UK, Kalita J. Clinical Neurophysiology $2^{\text {nd }}$ ed.New Delhi: Elsevier; 2006.

7. Duyff RF, Van den Bosch J, Laman DM, van Loon BJ, Linssen WH. Neuromuscular findings in thyroid dysfunction: a prospective clinical and electrodiagnostic study. J Neurol Neurosurg Psychiatry 2000 Jun;68(6):750-755.

8. Yüksel G, Karlikaya G, Tanridağ T, Us Ö, Akyüz G.Nerve Conduction Studies, SEP and Blink Reflex Studies in Recently Diagnosed, Untreated Thyroid Disease Patients. J Neurological Sci [Turkish] 2007;24(1):10:7-15.

9. Feibel JH, Campa JF.Thyrotoxic neuropathy (Basedow's paraplegia). J Neurol Neurosurg Psychiatry 1976;39(5):491-497.

10. Ludin HP, Spiess H, Koenig MP. Neuromuscular dysfunction associated with thyrotoxicosis. Eur Neurol 1969;2:269-278.

11. Roquer J, Cano JF. Carpal tunnel syndrome and hyperthyroidism. A prospective study. Acta Neurol Scand 1983;88:149-152.

12. Sözay S, Gökçe-Kutsal Y, Celiker R, Erbas T, Başgöze O. Neuroelectrophysiological evaluation of untreated hyperthyroid patients. Thyroidology 1994; 6(2): 55-59.

13. Sweed HS, Nasser AA, Khalil S, Bayomi I.Cognitive and Neuromuscular Assessment in Geriatric Patients with Thyroid Dysfunction. Egypt J Neurol Psychiat Neurosurg 2007;44(1): 235237.

14. Al-Wahaibi AK, Kumar S, Al-Risi A, Wali F. Thyrotoxic Neuropathy: A rare cause of acute flaccid paraplegia. Sultan Qaboos Univ Med J 2017;17(4):e460-e463.

15. Ajeena IM. Prevalence of Neuromuscular Abnormalities in Newly Diagnosed Patients with Thyroid Dysfunction. Am J Res Comm 2013;1(3):79-88.

16. Al-Wahaibi AK, Kumar S, Al-Risi A, Wali F. Thyrotoxic Neuropathy: A rare cause of acute flaccid paraplegia. Sultan Qaboos Univ Med J 2017;17(4):e460-e463. 